\title{
Oseltamivir in pregnancy and birth outcomes
}

\author{
Vera Ehrenstein ${ }^{1 *} \mathbb{D}$, Nickolaj Risbo Kristensen ${ }^{1}$, Brigitta Ursula Monz ${ }^{2}$, Barry Clinch ${ }^{3}$, Andy Kenwright ${ }^{3}$ \\ and Henrik Toft Sørensen ${ }^{1}$
}

\begin{abstract}
Background: Prenatal exposure to influenza or fever is associated with risk of congenital malformations. Oseltamivir is used to treat influenza and to provide post-exposure prophylaxis. We examined the association between oseltamivir use during pregnancy and birth outcomes.

Methods: This was a nationwide registry-based prevalence study with individual level data linkage, in a setting of universal health care access. We included all recorded pregnancies in Denmark in 2002-2013, and used data from population registries to examine associations between dispensings for oseltamivir during pregnancy (first trimester, second/third trimester, none) and congenital malformations, foetal death, preterm birth, foetal growth, and low 5-min Apgar score. Adjusted odds ratios (ORs) and 95\% confidence intervals (Cls) were computed using propensity score matching.

Results: The study included 946,176 pregnancies. Of these, 449 had first-trimester exposure and 1449 had second/ third-trimester exposure to oseltamivir. Adjusted ORs following first-trimester exposure were 0.94 ( $95 \% \mathrm{Cl} 0.49$ to 1.83) for any major congenital malformation and 1.75 ( $95 \% \mathrm{Cl} 0.51$ to 5.98) for congenital heart defects, based on 7 exposed cases. The association with congenital heart defects was present for etiologically implausible exposure periods and for known safe exposures. There was no evidence of an association between prenatal exposure to oseltamivir and any of the other birth outcomes assessed.
\end{abstract}

Conclusions: The study does not provide evidence of risk associated with oseltamivir treatment additional to that associated with influenza infection.

Keywords: Congenital abnormalities, Epidemiology, H1N1 influenza, Oseltamivir

\section{Background}

Influenza infection during first trimester of gestation is associated with a 2.0-fold increased risk of any major malformation; a 3.3-fold increased risk of neural tube defects; a 1.6-fold increased risk of congenital heart defects; and with increased risks of several other types of malformations $[1,2]$. Congenital heart defects are common, affecting 5-11 of 1000 live births [3], underscoring the importance of treatment and prevention of first-trimester viral infections and their sequelae. During the 2009-2010 pandemic, H1N1 influenza A infection was associated with adverse pregnancy outcomes $[4,5]$,

\footnotetext{
* Correspondence: ve@clin.au.dk

'Department of Clinical Epidemiology, Aarhus University Hospital, Olof

Palmes Allé 43-45, 8200 Aarhus N, Denmark

Full list of author information is available at the end of the article
}

while treatment with a neuraminidase inhibitor (NAI) was associated with reduced risks of admission to intensive care units and lower mortality among pregnant women $[4,6]$. Oseltamivir is a NAI used in treatment and post-exposure prophylaxis of influenza [7]. Evidence about pregnancy outcomes following oseltamivir exposure is reassuring [8-16], including a recent study based on routine health records from four European countries reporting no evidence of an increased risk of several birth outcomes following a NAI dispensing any time during gestation [16]. Nevertheless, previous studies had limitations, which include, potential selection bias from lack of data on abortuses, and potential misclassification of the outcome, which could dilute associations.

We examined safety of prenatal exposure to oseltamivir as measured by major congenital malformations,

(c) The Author(s). 2018 Open Access This article is distributed under the terms of the Creative Commons Attribution 4.0 International License (http://creativecommons.org/licenses/by/4.0/), which permits unrestricted use, distribution, and 
preterm birth, reduced foetal growth, low 5-min Apgar score, or foetal death. We addressed several limitations of previous studies by including pregnancies ending in abortive outcomes and ascertaining malformations through the first birthday; using a validated algorithm for congenital heart defects; and applying advanced methods of confounding control.

\section{Methods}

\section{Data sources}

We linked data from four population-based nationwide registries in Denmark: Danish Civil Registration System [17], Danish Medical Birth Registry [18], Danish National Patient Registry [19], and Danish National Prescription Registry [20]. Additional file 1: Table S1 provides a detailed description of all data sources, including specific types of data originating from each.

\section{Study design, population, and period}

We included all pregnancies in Denmark that started and ended between 01 January 2002 and 31 December 2013. Pregnancies ending in a live birth or a stillbirth ( $\geq 22$ gestational weeks) were identified in the Danish Medical Birth Registry. Pregnancies ending earlier than 22 gestational weeks in abortive outcomes were identified from hospital diagnoses recorded in the Danish National Patient Registry. Starting in 2007, the Danish National Patient Registry had information on congenital malformations identified during second-trimester therapeutic pregnancy terminations.

\section{Exposure}

The Danish National Prescription Registry provided information on dispensings for oseltamivir at outpatient (community) pharmacies. The following mutually exclusive categories of oseltamivir exposure during pregnancy were defined: exposure during the first trimester regardless of exposure in the second or third trimester; exposure during the second or the third trimester but not in the first trimester; and no exposure at any time during pregnancy (the reference category). Because organogenesis is complete in the first trimester, we examined association of first-trimester oseltamivir exposure with congenital malformations. For the remaining birth outcomes, oseltamivir exposure at any trimester was considered.

\section{Outcomes}

Congenital malformations, identified from diagnoses recorded at therapeutic second trimester abortions (2007-2013), at stillbirth, and up to 1 year postnatally in liveborn infants, were classified according to the major EUROCAT categories [3]. The Danish National Patient Registry is nearly 99\% complete for diagnoses of congenital malformations [21]. For congenital heart defects, we used an algorithm developed specifically for the Danish National Patient Registry, based on the EUROCAT-specified diagnostic codes combined with therapeutic cardiac procedures [22]. The positive predictive value of this algorithm, estimated on a random sample of cases observed in this study, was $94.6 \%$ (95\% confidence interval $89.2 \%$ to $97.7 \%$ ). The other pregnancy outcomes were stillbirth at $\geq 22$ weeks of gestation; foetal death (spontaneous or induced abortion before 22 weeks of gestation); preterm birth (gestational age 22- $<37$ weeks) among live and stillbirths; small for gestational age (SGA) (birth weight below 10th percentile of the sex- and gestational-week-specific weight distribution) among live and stillbirths; and low 5-min Apgar score $(<7)$ among live births. For non-singleton pregnancies, a given outcome was considered present if recorded in at least one foetus/newborn.

\section{Covariates}

We assessed the following covariates based on their known associations with the birth outcomes: maternal age at conception, calendar year of conception, smoking as reported at the first prenatal visit (for live and stillbirths); pre-pregnancy body mass index (BMI) for live and stillbirths; mode of delivery; parity; marital status; birth of a previous child with a malformation (since 1994); indicators of maternal health care utilization (hospitalizations, visits to hospital outpatient specialist clinics, emergency room visits, dispensings for specific drug classes); maternal inpatient or outpatient morbidity (respiratory disease, cardiovascular disease, haematological disease, diabetes, neurological disease, liver or kidney disease, rheumatic disease, inflammatory bowel disease, obesity, immunodeficiency, disorders of female pelvic organs/genital tract, hospital contact for injury or poisoning); maternal outpatient dispensings for antidepressants, antiepileptics, antidiabetics, antihypertensives, drugs for ulcer/ gastroesophageal reflux, oral contraceptives, drugs for in-vitro fertilization, thyroid hormones, systemic corticosteroids, non-steroidal anti-inflammatory drugs, opiates, and systemic anti-infective agents other than oseltamivir. Data on all diagnoses originated from inpatient or outpatient hospital diagnoses (secondary care), while data on medication dispensings originated from primary care and outpatient prescribing. The covariates were ascertained during 12 months preconception. Information on influenza status was not available from any data source. Definitions of the study variables appear in Additional file 1: Table S2 and Table S3.

\section{Statistical analyses}

We described the distributions of the pregnancy characteristics according to exposure to oseltamivir using 
appropriate descriptive statistics. For all outcomes except spontaneous or induced abortions, prevalence was used as the measure of occurrence. Crude and adjusted odds ratios (ORs) were computed using logistic regression. Pregnancies that ended before the second trimester were excluded from the analyses of second/ third trimester exposure. For abortions, incidence rate was used, with hazard ratios estimated via Cox's proportional-hazards regression, with oseltamivir exposure treated as a time-varying variable [23]. All estimates were reported with 95\% confidence intervals (CIs).

Confounding was addressed using two approaches: propensity score matching and conventional adjustment using multivariate regression with generalised estimating equations to account for within-woman correlation. Propensity score matching was considered superior in control of measured confounding, while conventional adjustment allowed use of all available observations and provided the context to evaluate the direction of estimates' change in response to tighter confounding control [24].

A propensity score for each pregnancy was computed, using logistic regression, as the probability of an oseltamivir dispensing given the covariates. Separate propensity scores were computed for the first-trimester and for the second/third-trimester exposure. Unexposed pregnancies were matched to exposed pregnancies on propensity score using nearest-neighbour matching with a caliper width of 0.2 standard deviations of the logit of the propensity score [25]. The balance of baseline characteristics was assessed post-matching, using standardised mean differences, whereby a value of $\leq 0.1$ was considered indicative of balance. Per protocol, up to 100 oseltamivir-unexposed pregnancies were planned to be matched to each oseltamivir-exposed pregnancy. Postmatching assessment of the resulting balance indicated that only 1:1 matching achieved the target covariate balance. This 1:1 matched sample was used in propensity-score analysis, as it was deemed to remove most of the measured confounding. The covariates included in the propensity scores and the balancing statistics before and after matching are described in Additional file 1: Tables S4-S5, and Figure S1.

In conventionally adjusted analyses, we included all covariates with prevalence $\geq 5 \%$ or those inducing a $>10 \%$ change in the crude OR. The final model included binary variables for parity $(0$ vs. $>0)$; marital status; smoking; obesity (BMI $\geq 30 \mathrm{~kg} / \mathrm{m}^{2}$ or a hospitalbased diagnosis of obesity); any chronic illness (cardiovascular disease, haematological disease, diabetes, neurological disease, liver or kidney disease, rheumatic disease or inflammatory bowel disease); and respiratory disease. In addition, all models included variables for mother's age at conception (as a cubic spline) and for prior delivery of a child with a malformation. Smoking is not recorded for pregnancies ending in abortive outcomes; therefore the sensitivity analyses that contained such pregnancies were not adjusted for smoking.

The main analyses were conducted based on pregnancies ending in a live or stillbirth using propensity score to control for confounding. Since confounding by indication was expected to persist in this setting, several prespecified and post hoc sensitivity analyses were conducted for the malformation outcomes to obtain indirect evidence on confounding extent. First, we repeated the main analyses while including malformation diagnoses from terminated pregnancies (for pregnancies in 2007-2013). Second, we excluded mothers with a prior delivery of a child with a malformation. Third, we assessed risks of malformations associated with dispensing for oseltamivir during the main organogenesis period (gestational weeks 4-10 [26]). Fourth, we conducted several 'negative control' analyses [27]: examining effects of oseltamivir dispensing during periods etiologically implausible with respect to inducing major malformations (12 to 3 months preconception; second/third trimester of pregnancy). Fifth, we repeated the analysis replacing first-trimester exposure to oseltamivir with first-trimester exposure to penicillin, which is an anti-infective agent without evidence of teratogenicity [28] but presumed to correlate with presence of an infectious process, including fever. Finally, we examined the distribution of specific types of congenital heart defects for potential clustering, as clustering would support a causal association.

The analyses were conducted using $\mathrm{SAS}^{\odot}$, version 9.4 (Cary, NC, USA). Results were presented only when the individual cell counts in tables exceeded 5 observations, as specified by the Danish Data Protection Law (www.datatilsynet.dk) and/or regulations of Statistics Denmark (www.dst.dk).

\section{Results}

Between 01 January 2002 and 31 December 2013, 948,819 pregnancies started and ended in Denmark. After excluding $2643(0.3 \%)$ pregnancies with invalid personal identifiers, 946,176 pregnancies remained in the analysis. Among these, 1898 (0.2\%) pregnancies were exposed to oseltamivir: 449 during the first trimester and 1449 during the second or third trimester (Fig. 1). Of the oseltamivir-exposed pregnancies, 92\% were exposed during 2009-2010. Table 1 presents characteristics of pregnancies included in the main analysis according to oseltamivir exposure, before and after propensity score matching.

Table 2 shows crude and adjusted odds ratios for the association of first-trimester exposure to oseltamivir with congenital malformations. Of the 19 first-trimester-exposed pregnancies with major congenital malformations, 8 were congenital heart defects. Among the 670,602 


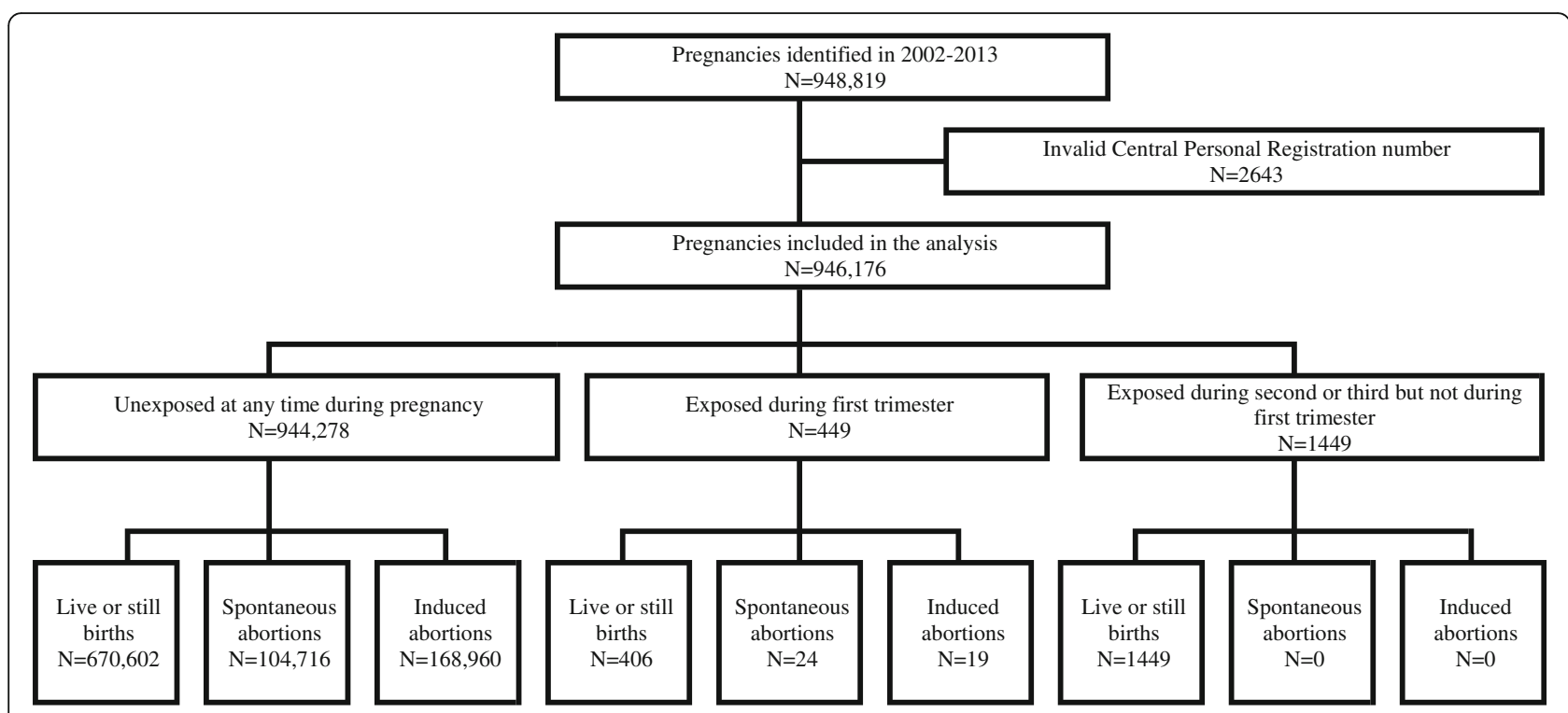

Fig. 1 Identification of pregnancies beginning and ending in 2002-2013, Denmark

oseltamivir-unexposed pregnancies, prevalence of any major malformation was $3.7 \%$ and prevalence of congenital heart defects was $0.7 \%$. Among the 406 pregnancies with first-trimester oseltamivir exposure, the prevalence of any malformation was $4.7 \%$ and the prevalence of congenital heart defects was $2.0 \%$. The odds ratios from propensity-score matched regression analysis were 0.94 (95\% CI 0.49 to 1.83 ) for any malformation and 1.75 (95\% CI 0.51 to 5.98 ) for congenital heart defects. Associations for congenital heart defects were also observed in the negative control sensitivity analyses of dispensing during second or third trimester (Table 3).

Table 4 presents results for the outcomes SGA, preterm birth, low 5-min Apgar score, and stillbirth. Based on propensity-score adjusted analyses, most odds ratios were close to 1.0. Some propensity-score-matched estimates were imprecise and therefore should be interpreted with caution. Table 5 shows the association between pregnancy exposure to oseltamivir and spontaneous or induced abortions, with oseltamivir as a timevarying exposure, based on 861 pregnancies exposed to oseltamivir. Adjusted incidence rate ratios associated with oseltamivir exposure were 0.99 (95\% CI 0.66 to 1.48) for spontaneous abortion and 0.64 (95\% CI 0.41 to 1.00) for induced abortion. No clustering of specific congenital heart defects was observed (data not shown).

\section{Discussion}

\section{Main findings}

In this population-based study, prenatal exposure to oseltamivir was not associated with increased risks of any major congenital malformation, foetal death, preterm birth, SGA or low 5-min Apgar score. For congenital heart defects, defined using a validated algorithm with high positive predictive value and completeness, exposure to oseltamivir during the first trimester was associated with an adjusted odds ratio of 1.75 (95\% CI 0.51 to 5.98) based on live and stillbirths, and with an adjusted odds ratio of 2.00 (95\% CI 0.60 to 6.64) after inclusion of malformations from terminated pregnancies. The association persisted for oseltamivir exposure in the second or third trimester, i.e., after completion of the organogenesis. There was no clustering of specific congenital heart defects among foetuses with first-trimester oseltamivir exposure. Because of low prevalence of oseltamivir exposure, associations with other major congenital malformations could not be evaluated.

\section{Limitations}

Important limitations of the present analysis are the low number of exposed cases and the lack of systematic data on influenza status. It is plausible to assume that during the 2009-2010 H1N1 influenza A pandemic, most oseltamivir use in pregnancy was therapeutic rather than prophylactic. This essentially guaranteed confounding by indication, especially since the unexposed pregnancies, the overwhelming majority of which were not affected by influenza, were used as the comparator in the analysis. An ideal comparator population would be composed of pregnancies affected by influenza but not treated with oseltamivir to provide the background risk of outcomes in influenza affected population. Instead, the comparator population of unexposed pregnancies 
Table 1 Characteristics of pregnancies resulting in a live or still birth, by exposure to oseltamivir

\begin{tabular}{|c|c|c|c|c|c|c|c|}
\hline \multirow[t]{2}{*}{ Characteristic } & \multicolumn{3}{|c|}{ Before propensity score matching } & \multicolumn{4}{|c|}{ After propensity score matching } \\
\hline & $\begin{array}{l}\text { Unexposed to } \\
\text { oseltamivir } \\
\text { during pregnancy }\end{array}$ & $\begin{array}{l}\text { Exposed } \\
\text { during first } \\
\text { trimester }\end{array}$ & $\begin{array}{l}\text { Exposed during } \\
\text { second or third } \\
\text { trimester }\end{array}$ & $\begin{array}{l}\text { Unexposed to } \\
\text { oseltamivir } \\
\text { during pregnancy }\end{array}$ & $\begin{array}{l}\text { Exposed } \\
\text { during first } \\
\text { trimester }\end{array}$ & $\begin{array}{l}\text { Unexposed to } \\
\text { oseltamivir } \\
\text { during pregnancy } \\
\end{array}$ & $\begin{array}{l}\text { Exposed during } \\
\text { second or third } \\
\text { trimester }\end{array}$ \\
\hline Number & 670,602 & 406 & 1449 & 397 & 397 & 1420 & 1420 \\
\hline \multicolumn{8}{|l|}{ Age at conception (years) } \\
\hline$<20$ & $14,636(2.2)$ & $11(2.7)$ & $32(2.2)$ & $6(1.5)$ & $11(2.8)$ & $23(1.6)$ & $31(2.2)$ \\
\hline $20-35$ & $549,563(82.0)$ & $310(76.4)$ & $1114(76.9)$ & $301(75.8)$ & $303(76.3)$ & $1109(78.1)$ & $1088(76.6)$ \\
\hline$\geq 35$ & $106,403(15.9)$ & $85(20.9)$ & $303(20.9)$ & $90(22.7)$ & $83(20.9)$ & $288(20.3)$ & $301(21.2)$ \\
\hline \multicolumn{8}{|l|}{ Age at conception (years) } \\
\hline Median (IQR) & $30(26-33)$ & $30(27-34)$ & $30(27-34)$ & $31(27-34)$ & $30(27-34)$ & $31(27-34)$ & $30(27-34)$ \\
\hline Mean (SD) & $30.0(4.9)$ & $30.7(5.0)$ & $30.8(4.9)$ & $31.1(4.9)$ & $30.8(5.0)$ & $31.0(4.8)$ & $30.8(4.9)$ \\
\hline \multicolumn{8}{|l|}{ Calendar year of conception } \\
\hline $2002-2008$ & $426,697(63.6)$ & $18(4.4)$ & $60(4.1)$ & $241(60.7)$ & $18(4.5)$ & $845(59.5)$ & $60(4.2)$ \\
\hline 2009-2010 & 118,496 (17.7) & $376(92.6)$ & 1335 (92.1) & 78 (19.6) & $367(92.4)$ & $265(18.7)$ & $1310(92.3)$ \\
\hline $2011-2013$ & 125,409 (18.7) & $12(3.0)$ & $54(3.7)$ & 78 (19.6) & $12(3.0)$ & $310(21.8)$ & $50(3.5)$ \\
\hline Unmarried & 357,106 (53.3) & $191(47.0)$ & $663(45.8)$ & $184(46.3)$ & $185(46.6)$ & $623(43.9)$ & $645(45.4)$ \\
\hline \multicolumn{8}{|c|}{ Pre-pregnancy body mass index $\left(\mathrm{kg} / \mathrm{m}^{2}\right)$} \\
\hline$<18.5$ & 24,336 (3.6) & $20(4.9)$ & $46(3.2)$ & $6(1.5)$ & $20(5.0)$ & $55(3.9)$ & $46(3.2)$ \\
\hline $18.5-<25.0$ & $355,498(53.0)$ & $238(58.6)$ & 835 (57.6) & $204(51.4)$ & $233(58.7)$ & 766 (53.9) & $822(57.9)$ \\
\hline $25.0-<30.0$ & $118,521(17.7)$ & $84(20.7)$ & $305(21.0)$ & 75 (18.9) & $83(20.9)$ & $269(18.9)$ & $300(21.1)$ \\
\hline$\geq 30$ & $70,259(10.5)$ & $54(13.3)$ & $212(14.6)$ & $48(12.1)$ & $52(13.1)$ & $166(11.7)$ & $206(14.5)$ \\
\hline Missing & $101,988(15.2)$ & $10(2.5)$ & $51(3.5)$ & $64(16.1)$ & $9(2.3)$ & $164(11.5)$ & $46(3.2)$ \\
\hline \multicolumn{8}{|l|}{ Smoking } \\
\hline No & 561,830 (83.8) & $351(86.5)$ & $1258(86.8)$ & $358(90.2)$ & $351(88.4)$ & 1275 (89.8) & $1258(88.6)$ \\
\hline Yes & $95,528(14.2)$ & $46(11.3)$ & $162(11.2)$ & $39(9.8)$ & $46(11.6)$ & $145(10.2)$ & $162(11.4)$ \\
\hline Missing $^{a}$ & 13,244 (2.0) & $9(2.2)$ & $29(2.0)$ & - & - & - & - \\
\hline \multicolumn{8}{|l|}{ Parity } \\
\hline 0 & 314,229 (46.9) & $136(33.5)$ & $441(30.4)$ & $122(30.7)$ & $132(33.2)$ & $415(29.2)$ & $427(30.1)$ \\
\hline 1 & $242,531(36.2)$ & $183(45.1)$ & $637(44.0)$ & $187(47.1)$ & $179(45.1)$ & $654(46.1)$ & $627(44.2)$ \\
\hline 2 & $86,863(13.0)$ & $64(15.8)$ & $296(20.4)$ & $67(16.9)$ & $63(15.9)$ & $270(19.0)$ & $292(20.6)$ \\
\hline$>2$ & $26,979(4.0)$ & $23(5.7)$ & $75(5.2)$ & $21(5.3)$ & $23(5.8)$ & $81(5.7)$ & $74(5.2)$ \\
\hline $\begin{array}{l}\text { Prior delivery of a child with a } \\
\text { malformation (since 1994) }\end{array}$ & $20,171(3.0)$ & $16(3.9)$ & $67(4.6)$ & $19(4.8)$ & $16(4.0)$ & $72(5.1)$ & $64(4.5)$ \\
\hline \multicolumn{8}{|c|}{ Hospital history during 12 months before conception ${ }^{\text {b }}$} \\
\hline $\begin{array}{l}\text { At least one inpatient } \\
\text { hospitalization }\end{array}$ & $124,627(18.6)$ & $83(20.4)$ & $334(23.1)$ & $75(18.9)$ & 79 (19.9) & $270(19.0)$ & $327(23.0)$ \\
\hline $\begin{array}{l}\text { At least one visit to } \\
\text { outpatient specialist clinic }\end{array}$ & $232,129(34.6)$ & $169(41.6)$ & $609(42.0)$ & $155(39.0)$ & $165(41.6)$ & $570(40.1)$ & $597(42.0)$ \\
\hline $\begin{array}{l}\text { At least one emergency } \\
\text { room visit }\end{array}$ & $85,760(12.8)$ & $80(19.7)$ & $215(14.8)$ & $69(17.4)$ & $77(19.4)$ & $180(12.7)$ & $211(14.9)$ \\
\hline Respiratory diseases & $33,405(5.0)$ & $39(9.6)$ & $90(6.2)$ & $38(9.6)$ & $39(9.8)$ & $89(6.3)$ & $89(6.3)$ \\
\hline Cardiovascular disease & $7760(1.2)$ & $7(1.7)$ & $30(2.1)$ & $5(1.3)$ & $6(1.5)$ & $15(1.1)$ & $29(2.0)$ \\
\hline Haematological disease & $2364(0.4)$ & $5(1.2)$ & $15(1.0)$ & $0(0.0)$ & $5(1.3)$ & $8(0.6)$ & $15(1.1)$ \\
\hline Diabetes & $10,590(1.6)$ & $5(1.2)$ & $38(2.6)$ & $7(1.8)$ & $5(1.3)$ & $29(2.0)$ & $37(2.6)$ \\
\hline Neurological disease ${ }^{b}$ & $5654(0.8)$ & $5(1.2)$ & $20(1.4)$ & - & - & - & - \\
\hline Obesity $^{c}$ & $73,216(10.9)$ & $56(13.8)$ & $222(15.3)$ & $49(12.3)$ & $54(13.6)$ & $174(12.3)$ & $216(15.2)$ \\
\hline
\end{tabular}


Table 1 Characteristics of pregnancies resulting in a live or still birth, by exposure to oseltamivir (Continued)

\begin{tabular}{|c|c|c|c|c|c|c|c|}
\hline \multirow[t]{2}{*}{ Characteristic } & \multicolumn{3}{|c|}{ Before propensity score matching } & \multicolumn{4}{|c|}{ After propensity score matching } \\
\hline & $\begin{array}{l}\text { Unexposed to } \\
\text { oseltamivir } \\
\text { during pregnancy }\end{array}$ & $\begin{array}{l}\text { Exposed } \\
\text { during first } \\
\text { trimester }\end{array}$ & $\begin{array}{l}\text { Exposed during } \\
\text { second or third } \\
\text { trimester }\end{array}$ & $\begin{array}{l}\text { Unexposed to } \\
\text { oseltamivir } \\
\text { during pregnancy }\end{array}$ & $\begin{array}{l}\text { Exposed } \\
\text { during first } \\
\text { trimester }\end{array}$ & $\begin{array}{l}\text { Unexposed to } \\
\text { oseltamivir } \\
\text { during pregnancy }\end{array}$ & $\begin{array}{l}\text { Exposed during } \\
\text { second or third } \\
\text { trimester }\end{array}$ \\
\hline $\begin{array}{l}\text { Disorders of female pelvic } \\
\text { organs/genital tract }\end{array}$ & $44,730(6.7)$ & $32(7.9)$ & $86(5.9)$ & $25(6.3)$ & $32(8.1)$ & $70(4.9)$ & $84(5.9)$ \\
\hline $\begin{array}{l}\text { Hospital contact for } \\
\text { injury or poisoning }\end{array}$ & $60,037(9.0)$ & $51(12.6)$ & $148(10.2)$ & $51(12.8)$ & $50(12.6)$ & $130(9.2)$ & $144(10.1)$ \\
\hline \multicolumn{8}{|c|}{ Use of prescription medication in the 12 months before conception } \\
\hline Antidepressants & $34,293(5.1)$ & $30(7.4)$ & $115(7.9)$ & $29(7.3)$ & $29(7.3)$ & $105(7.4)$ & $109(7.7)$ \\
\hline $\begin{array}{l}\text { Drugs for ulcer/ } \\
\text { gastroesophageal reflux }\end{array}$ & $26,456(3.9)$ & $27(6.7)$ & $84(5.8)$ & $18(4.5)$ & $26(6.5)$ & $80(5.6)$ & $83(5.8)$ \\
\hline Oral contraceptives & $243,936(36.4)$ & $156(38.4)$ & $534(36.9)$ & $173(43.6)$ & $153(38.5)$ & $517(36.4)$ & $523(36.8)$ \\
\hline $\begin{array}{l}\text { Drugs for in-vitro } \\
\text { fertilization }\end{array}$ & $54,563(8.1)$ & $43(10.6)$ & $116(8.0)$ & $35(8.8)$ & $43(10.8)$ & $103(7.3)$ & $114(8.0)$ \\
\hline Thyroid hormones & $7284(1.1)$ & $8(2.0)$ & $25(1.7)$ & $8(2.0)$ & $8(2.0)$ & $31(2.2)$ & $24(1.7)$ \\
\hline Systemic corticosteroids & $13,005(1.9)$ & $17(4.2)$ & $49(3.4)$ & $17(4.3)$ & $16(4.0)$ & $41(2.9)$ & $49(3.5)$ \\
\hline $\begin{array}{l}\text { Non-steroidal anti- } \\
\text { inflammatory drugs }\end{array}$ & $98,907(14.7)$ & $78(19.2)$ & $268(18.5)$ & $66(16.6)$ & $77(19.4)$ & $252(17.7)$ & $261(18.4)$ \\
\hline Opiates & $21,777(3.2)$ & $18(4.4)$ & $58(4.0)$ & $17(4.3)$ & $17(4.3)$ & $76(5.4)$ & $57(4.0)$ \\
\hline $\begin{array}{l}\text { Systemic anti-infective } \\
\text { agents other than } \\
\text { oseltamivir }\end{array}$ & $278,680(41.6)$ & $195(48.0)$ & $734(50.7)$ & $189(47.6)$ & $190(47.9)$ & $740(52.1)$ & $719(50.6)$ \\
\hline $\begin{array}{l}\text { Number of different drugs } \\
\text { classes dispensed, median (IQR) }\end{array}$ & $1(1-2)$ & $2(1-3)$ & $2(1-3)$ & $2(1-3)$ & $2(1-3)$ & $2(1-3)$ & $2(1-3)$ \\
\hline
\end{tabular}

IQR interquartile range, SD standard deviation

${ }^{a}$ Matching of the unexposed pregnancies was done separately for those exposed in the first trimester and those exposed in the second or third trimester. No matching of pregnancies with missing data on smoking

${ }^{b}$ Not reported for the following protocol-specified characteristics because of low $(<5)$ group counts: liver and kidney disease; rheumatic disease; inflammatory bowel disease; immunodeficiency, and use of antiepileptics. In the propensity-score matched dataset neurologic diseases also not reported. 'Defined by prepregnancy body mass index or a hospital diagnosis of obesity. Data are $n(\%)$ unless otherwise specified

represented the prevalence of congenital malformations in the general Danish population, i.e., an overall prevalence of malformations close to that reported for Denmark by the EUROCAT, based on a representative sample (2002-2012 total prevalence per 1000 births: 30 [95\% CI 28 to 31] for any malformation; 9.1 [95\% CI 8.4 to 10.0] for congenital heart defects [3]). The most recent analysis involving Scandinavian data [16] excluded pregnancies with a hospital-based diagnosis of influenza. This was done to reduce confounding by indication, but may have potentially introduced selection bias by excluding the most severely affected pregnancies from the study population. In our study, excluding women with a hospital diagnosis of influenza did not materially affect the findings (conventionally adjusted OR for any major congenital malformation 1.20 [95\% CI: 0.74 to 1.95$])$.

Several considerations point to residual confounding These include increasing attenuation of odds ratios in response to closer confounding control; persisting

Table 2 First-trimester exposure to oseltamivir and congenital malformations among live or stillbirths

\begin{tabular}{|c|c|c|c|c|c|}
\hline \multirow[t]{2}{*}{ Outcome } & \multirow{2}{*}{$\begin{array}{l}\text { Unexposed } \\
N=670,602\end{array}$} & \multirow{2}{*}{$\begin{array}{l}\text { Exposed } \\
N=406\end{array}$} & \multirow{2}{*}{$\begin{array}{l}\text { Crude odds ratio } \\
(95 \% \mathrm{Cl})\end{array}$} & \multicolumn{2}{|c|}{ Adjusted odds ratio (95\% Cl) } \\
\hline & & & & $\begin{array}{l}\text { Conventional regression } \\
\text { analysis }^{\mathrm{a}}\end{array}$ & $\begin{array}{l}\text { Propensity-score matched } \\
\text { regression analysis }^{\mathrm{b}}\end{array}$ \\
\hline Any major congenital malformation & $24,773(3.7 \%)$ & $19(4.7 \%)$ & 1.28 (0.81 to 2.03$)$ & 1.25 (0.78 to 2.01$)$ & 0.94 (0.49 to 1.83 ) \\
\hline Congenital heart defects & $4795(0.7 \%)$ & $8(2.0 \%)$ & 2.79 (1.39 to 5.62$)$ & $2.51(1.19$ to 5.31$)$ & $1.75(0.51$ to 5.98$)$ \\
\hline
\end{tabular}

${ }^{a}$ Adjusted for age at conception, parity, smoking, marital status, obesity, prior delivery of a child with a malformation, respiratory diseases, any other chronic illness (cardiovascular disease, haematological disease, diabetes, neurological disease [including antidepressants or antiepileptics use], liver or kidney disease, rheumatic disease or inflammatory bowel disease) during the 12 months before conception

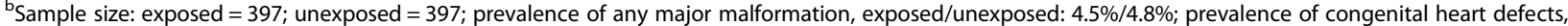
exposed/unexposed: $1.8 \% / 1.0 \%$ 
Table 3 Sensitivity analyses of the outcome of congenital malformations following exposure to oseltamivir in pregnancy

\begin{tabular}{|c|c|c|c|c|c|c|}
\hline & \multicolumn{3}{|c|}{ Conventional regression analysis } & \multicolumn{3}{|c|}{ Propensity-score matched regression analysis } \\
\hline & Unexposed & Exposed & Odds ratio $(95 \% \mathrm{Cl})^{\mathrm{a}}$ & Unexposed & Exposed & Odds ratio $(95 \% \mathrm{Cl})^{\mathrm{b}}$ \\
\hline \multicolumn{7}{|c|}{ Analysis including pregnancies terminated due to congenital malformations (2007-2013), prespecified } \\
\hline Number & 521,037 & 432 & & 432 & 432 & \\
\hline Any major congenital malformation & $16,692(3.2 \%)$ & $22(5.1 \%)$ & 1.58 (1.03 to 2.44$)$ & $20(4.6 \%)$ & $22(5.1 \%)$ & 1.10 (0.60 to 2.02) \\
\hline Congenital heart defects & $3005(0.6 \%)$ & $8(1.9 \%)$ & 3.17 (1.57 to 6.40$)$ & $4(0.9 \%)$ & $8(1.9 \%)$ & $2.00(0.60$ to 6.64$)$ \\
\hline \multicolumn{7}{|c|}{ Pregnancies among women without an earlier pregnancy resulting in a malformed child, post hoc } \\
\hline Number & 650,431 & 390 & & 381 & 381 & \\
\hline Any major malformation & $23,712(3.7 \%)$ & $18(4.6 \%)$ & $1.26(0.77$ to 2.04$)$ & $20(5.3 \%)$ & $17(4.5 \%)$ & $0.84(0.43$ to 1.64$)$ \\
\hline Congenital heart defects & $4598(0.7 \%)$ & $8(2.1 \%)$ & 2.68 (1.27 to 5.68$)$ & $5(1.3 \%)$ & $7(1.8 \%)$ & 1.50 (0.42 to 5.32$)$ \\
\hline
\end{tabular}

First trimester exposure to oseltamivir, defined as oseltamivir dispensing during 4-10 weeks of gestation, post hoc

\begin{tabular}{|c|c|c|c|c|c|c|}
\hline Number & 670,602 & 212 & & 205 & 205 & \\
\hline Any major malformation & $24,773(3.7 \%)$ & $8(3.8 \%)$ & 0.91 (0.43 to 1.95$)$ & $8(3.9 \%)$ & 7 (3.4\%) & 0.88 (0.32 to 2.41$)$ \\
\hline Congenital heart defects & $4795(0.7 \%)$ & $5(2.4 \%)$ & $2.70(1.00$ to 7.29$)$ & N/A & & \\
\hline
\end{tabular}

Oseltamivir dispensing in second or third trimester (post-organogenesis), prespecified

$\begin{array}{lcccccc}\text { Number } & 670,602 & 1449 & & 1420 & 1420 \\ \text { Any major malformation } & 24,773(3.7 \%) & 64(4.4 \%) & 1.18(0.91 \text { to } 1.53) & 51(3.6 \%) & 61(4.3 \%) & 1.21(0.82 \text { to } 1.77) \\ \text { Congenital heart defects } & 4795(0.7 \%) & 21(1.5 \%) & 2.10(1.36 \text { to } 3.24) & 6(0.4 \%) & 21(1.5 \%) & 3.50(1.41 \text { to } 8.67)\end{array}$

Exposure to oseltamivir between 12 and 3 months preconception, post hoc

\begin{tabular}{|c|c|c|c|c|c|c|}
\hline Number & 669,934 & 538 & & 530 & 530 & \\
\hline Any major malformation & 24,745 (3.7\%) & $24(4.5 \%)$ & 1.20 (0.80 to 1.80$)$ & 19 (3.6\%) & $24(4.5 \%)$ & 1.28 (0.69 to 2.37 ) \\
\hline Congenital heart defects & N/A & & & & & \\
\hline
\end{tabular}

First-trimester exposure to penicillin, post hoc ${ }^{c}$

\begin{tabular}{lcccc} 
Number & 471,117 & 70,309 & & Analysis not conducted \\
Any major malformation & $17,148(3.6 \%)$ & $2798(4.0 \%)$ & $1.09(1.04$ to 1.13$)$ & \\
Congenital heart defects & $3296(0.7 \%)$ & $599(0.9 \%)$ & $1.17(1.07$ to 1.29$)$ & \\
\hline
\end{tabular}

$\mathrm{Cl}$ confidence interval, N/A not applicable (counts too low to report)

${ }^{a}$ Adjusted for age at conception, parity, smoking, marital status, obesity, prior delivery of a child with a malformation, respiratory diseases, any other chronic illness (cardiovascular disease, haematological disease, diabetes, neurological disease [including use of antidepressants or antiepileptics], liver or kidney disease, rheumatic disease, or inflammatory bowel disease) during 12 months before conception

b Variables included in estimation of propensity scores are listed in the Additional file 1

${ }^{\mathrm{C}}$ Exposure to penicillin for malformations (any, congenital heart defects) among live born and stillborn infants conceived and delivered in $2002-2013$ in Denmark

associations for the negative control exposures, for which no association was expected unless caused by confounding - i.e., in periods after the organogenesis is expected to be complete. At the same time, the ORs for congenital heart defects were similar to those reported in other studies for first-trimester fever (1.54 [95\% CI 1.37 to 1.74]) [29] or first-trimester influenza infection (1.56 [95\% CI 1.13 to 2.14]) [1]. The lower precision of the odds ratios obtained in the propensity score matched analysis was the trade-off taken for maximising validity via 1:1 matching. Other limitations of this analysis are potential misclassification of exposure status by relying on dispensing records, by lack of information on oseltamivir dispensed during hospital stays, and by potential errors in recorded gestational age.

\section{Other evidence}

Taken together, the available evidence is not consistent with harmful pregnancy effects of oseltamivir or other NAIs [8, 10-16]. A Canadian study of more than 55,000 pregnant women, including $1237 \mathrm{ex}-$ posed to oseltamivir during the $\mathrm{H} 1 \mathrm{~N} 1$ pandemic, reported no evidence of an association between prenatal exposure to oseltamivir and preterm birth, low Apgar scores, or poor foetal growth [12]. Similarly, a study in Texas based on 135 oseltamivir-exposed pregnancies did not suggest harmful pregnancy effects [13]. The most recent study, conducted by Graner et al. [16], used linked databases from four European countries, including the same source data for Denmark as used in the current study and investigated similar outcomes. 
Table 4 Prenatal exposure to oseltamivir and SGA, preterm birth, low 5-min Apgar score, and stillbirth

\begin{tabular}{|c|c|c|c|c|c|}
\hline & Unexposed & Exposed & $\begin{array}{l}\text { Crude odds } \\
\text { ratio }(95 \% \mathrm{Cl})\end{array}$ & $\begin{array}{l}\text { Conventional regression } \\
\text { analysis, odds ratio }(95 \% \mathrm{Cl})\end{array}$ & $\begin{array}{l}\text { Propensity score-matched regression } \\
\text { analysis, odds ratio }(95 \% \mathrm{Cl})^{c}\end{array}$ \\
\hline \multicolumn{6}{|l|}{ First trimester } \\
\hline Number & 670,602 & 406 & & & \\
\hline Small for gestational age & $64,944(9.7 \%)$ & $32(7.9 \%)$ & 0.80 (0.56 to 1.14$)$ & 0.88 (0.61 to 1.26$)$ & 0.75 (0.46 to 1.24$)$ \\
\hline Preterm birth & $42,399(6.3 \%)$ & $28(6.9 \%)$ & 1.10 (0.75 to 1.61$)$ & 1.21 (0.83 to 1.79$)$ & 0.87 (0.52 to 1.46$)$ \\
\hline Low 5-min Apgar score ${ }^{a}$ & $5429(0.8 \%)$ & $5(1.2 \%)$ & 1.52 (0.63 to 3.68$)$ & 1.64 (0.68 to 3.97$)$ & 1.00 (0.29 to 3.45$)$ \\
\hline \multicolumn{6}{|l|}{ Second/third trimester } \\
\hline Number & 670,602 & 1449 & & & \\
\hline Small for gestational age & $64,944(9.7 \%)$ & $121(8.3 \%)$ & 0.85 (0.71 to 1.02$)$ & 0.94 (0.77 to 1.13$)$ & 0.84 (0.64 to 1.10$)$ \\
\hline Preterm birth & $42,399(6.3 \%)$ & 79 (5.4\%) & 0.85 (0.68 to 1.07$)$ & 0.89 (0.70 to 1.12$)$ & 0.85 (0.62 to 1.16$)$ \\
\hline Low 5-min Apgar score ${ }^{a}$ & $5429(0.8 \%)$ & $10(0.7 \%)$ & 0.85 (0.46 to 1.59$)$ & 0.92 (0.49 to 1.71$)$ & 1.25 (0.49 to 3.17$)$ \\
\hline Stillbirth ${ }^{\mathrm{b}}$ & $3047(0.4 \%)$ & $7(0.5 \%)$ & 1.06 (0.51 to 2.24) & 1.13 (0.50 to 2.52$)$ & $1.20(0.37$ to 3.93$)$ \\
\hline
\end{tabular}

Data are $\mathrm{n}(\%)$ or odds ratio $(95 \% \mathrm{Cl})$ unless otherwise specified

SGA small for gestational age, $\mathrm{Cl}$ confidence interval

a Live born only

${ }^{b}$ Live or stillborn at $\geq 22$ weeks of gestation; data not shown for first-trimester exposure because of low counts

Variables included in estimation of propensity scores are listed in the Additional file 1

Graner et al. identified seven cases of congenital heart malformations in 814 first trimester oseltamivir-exposed pregnancies, resulting in a (conventionally) adjusted odds ratio of 0.96 (95\% CI 0.43 to 2.15). Our study detected eight congenital heart defects in less than half as many exposed pregnancies $(N=406)$. This may be explained by the extension of the case detection period to up to 1 year postnatally. The differences in the conventionally adjusted odds ratios in our study compared with the study by Graner et al. (2.51 versus 0.96 ) may have resulted from our decision not to exclude pregnancies with hospital influenza diagnoses, combined with the higher prevalence of congenital heart defects among offspring of exposed women in our study population.

\section{Interpretation}

The OR for congenital heart defects associated with the first-trimester exposure to oseltamivir was of comparable size to that reported for influenza infection or fever, indicating that despite close control of confounding, in the setting of pregnancy, a nearly full confounding by influenza status is likely. The association was also observed during etiologically implausible periods, such as periods after completion of organogenesis; furthermore, the ORs weakened in response to successive control of measured confounding, from crude ORs (fully confounded) to conventionally adjusted ORs (some residual confounding) to propensity-score adjusted ORs (least residual confounding). Lack of clustering of specific congenital heart defects among foetuses with first-trimester oseltamivir exposure although does not disprove it, argues against the causality underlying the observed association [30]. Thus, this study in the context of the available evidence is consistent with adverse pregnancy outcomes being associated with influenza infection itself.

\section{Conclusions}

The study does not provide evidence of risk associated with oseltamivir treatment additional to that previously known to be associated with influenza infection.

Table 5 Exposure to oseltamivir in pregnancy and spontaneous or induced abortions

\begin{tabular}{|c|c|c|c|c|c|c|}
\hline \multirow{2}{*}{$\begin{array}{l}\text { Type of abortion } \\
\text { Spontaneous or induced }\end{array}$} & \multicolumn{2}{|c|}{ Exposed $^{a}$} & \multicolumn{2}{|c|}{ Unexposed } & \multirow{2}{*}{$\begin{array}{c}\text { Crude hazard ratio }(95 \% \mathrm{Cl}) \\
0.77(0.57 \text { to } 1.04)\end{array}$} & \multirow{2}{*}{$\begin{array}{c}\text { Adjusted }^{\mathrm{b}} \text { hazard ratio }(95 \% \mathrm{Cl}) \\
0.79(0.59 \text { to } 1.07)\end{array}$} \\
\hline & 43 & 122 & 273,676 & 293,663 & & \\
\hline Spontaneous & 24 & 122 & 104,716 & 293,663 & $1.00(0.67$ to 1.50$)$ & 0.99 (0.66 to 1.48$)$ \\
\hline Induced & 19 & 122 & 168,960 & 293,663 & 0.59 (0.38 to 0.93$)$ & 0.64 (0.41 to 1.00$)$ \\
\hline
\end{tabular}

Cl confidence interval

${ }^{a}$ Based on 861 gestations exposed to oseltamivir

${ }^{\mathrm{b}}$ Adjusted for age at conception, parity, smoking, marital status, obesity, prior delivery of a child with a malformation, respiratory diseases, any other chronic illness [cardiovascular disease, haematological disease, diabetes, neurological disease (including use of antidepressants or antiepileptics), liver or kidney disease, rheumatic disease or inflammatory bowel disease] during 12 months before conception

'Exposure to oseltamivir is analysed as time-varying variable 


\section{Additional file}

Additional file 1: Online supplement to Ehrenstein et al. Oseltamivir in pregnancy and birth outcomes. Table S1. Danish registries used to assemble the analysis dataset. Table S2. ATC, ICD, and procedure codes used to identify study variables other than congenital malformations. Table S3. EUROCAT algorithms to identify major congenital malformations. Table S4. Types of propensity scores and analysis sets. Table S5. Post-matching mean differences in variables included in propensity score estimation. Figure S1. Distribution of propensity score in the matched sample for first-trimester (A) or second/third trimester (B) exposure to oseltamivir and the 1:1 matched unexposed pregnancies. (DOCX $217 \mathrm{~kb})$

\section{Abbreviations}

BMI: Body mass index; Cl: Confidence interval; ICD-10: International Classification of Diseases, Tenth Revision; IQR: Interquartile range; N/A: Not applicable; NAI: Neuraminidase inhibitor; OR: Odds ratio; SD: Standard deviation; SGA: Small for gestational age

\section{Acknowledgements}

We are grateful to Dr. Morten Olsen for expert advice on cardiac malformations and for conducting the case adjudication; and to the research nurses Henriette Kristoffersen and Hanne Moeslund Madsen for medical chart abstraction.

\section{Funding}

This study was funded by F. Hoffmann-La Roche Ltd. through an institutional research agreement with Aarhus University. It was designed as a PostAuthorization Safety Study in consultation with the European Medicines Agency). Employees of the funding source (BM, BC, and AK) were involved in the study design, the interpretation of data, writing of the manuscript, and the decision to submit the paper for publication. The funding source was not involved in collection or analysis of data. All authors had full access to all analysis outputs and results. The corresponding author had final responsibility for the decision to submit for publication.

\section{Availability of data and materials}

The data that support the findings of this study are available from Statistics Denmark, but restrictions apply to the availability of these data, which were used under permission exclusive to the current study, and so are not publicly available. Data access may be available by a special and reasonable request to the authors and with permission of and upon application to Statistics Denmark, and the Danish Data Protection Agency or any other agency as required by Danish law.

\section{Authors' contributions}

VE contributed to the study design, oversaw the analyses, drafted the manuscript, and revised it critically for important intellectual content. NRK contributed to the study design, conducted the data analyses, and revised the manuscript critically for important intellectual content. BUM contributed to study design, oversaw the analyses and contributed to interpretation of results. BC provided clinical expertise, and contributed to study design. AK provided statistical expertise and contributed to the analytic strategy. HTS contributed to the study design, acquired the data, and provided clinical and epidemiologic expertise. All authors critically revised the manuscript for intellectual contents. The authors listed above approved the version to be submitted and agree to be accountable for all aspects of the work in ensuring that questions related to the accuracy or integrity of any part of the work are appropriately investigated and resolved. All authors read and approved the final manuscript.

\section{Ethics approval and consent to participate}

The study received a required approval by the Danish Data Protection Agency [record numbers 2015-57-0002 (previously 2015-41-3838) and 201341-1754]. The study protocol is registered as Post-Authorisation Safety Study with the ENCePP Register of Studies, with study number EUPAS12875 (Roche identifier: BV29684). There is no requirement by Danish law to obtain informed consent or an approval by an Institutional Review Board for a registry-based study.

\section{Consent for publication}

Not applicable.

\section{Competing interests}

BM, BC and AK are full-time employees and hold stock and/or stock options in Roche, the manufacturer of oseltamivir. VE, NRK, and HTS are salaried employees of Aarhus University/Aarhus University Hospital. HTS is supported by the Program for Clinical Research Infrastructure (PROCRIN), established by the Lundbeck Foundation and the Novo Nordisk Foundation and administered by the Danish Regions. This study was funded by F. Hoffmann-La Roche Ltd. through a research agreement to and administered by Aarhus University.

\section{Publisher's Note}

Springer Nature remains neutral with regard to jurisdictional claims in published maps and institutional affiliations.

\section{Author details}

${ }^{1}$ Department of Clinical Epidemiology, Aarhus University Hospital, Olof Palmes Allé 43-45, 8200 Aarhus N, Denmark. F. Hoffmann-La Roche Ltd., Basel, Switzerland. ${ }^{3}$ Roche Products Ltd., Welwyn Garden City, UK.

Received: 5 October 2017 Accepted: 27 September 2018 Published online: 16 October 2018

\section{References}

1. Luteijn JM, Brown MJ, Dolk H. Influenza and congenital anomalies: a systematic review and meta-analysis. Hum Reprod. 2014;29:809-23.

2. Acs N, Banhidy F, Puho E, Czeizel AE. Maternal influenza during pregnancy and risk of congenital abnormalities in offspring. Birth Defects Res A Clin Mol Teratol. 2005;73:989-96.

3. European Surveillance of Congenital Anomalies EUROCAT Guide 1.4, Section 3.3 EUROCAT Subgroups of Congenital Anomalies (Version 2014). 2014. http://www.eurocat-network.eu/content/EUROCAT-Guide-1.4-Section-3.3.pdf. Accessed 16 July 2017

4. Mosby LG, Rasmussen SA, Jamieson DJ. 2009 pandemic influenza A (H1N1) in pregnancy: a systematic review of the literature. Am J Obstet Gynecol. 2011;205:10-8

5. Pierce $M$, Kurinczuk JJ, Spark $P$, Brocklehurst $P$, Knight $M$. Perinatal outcomes after maternal 2009/H1N1 infection: national cohort study. BMJ. 2011;342: d3214.

6. Muthuri SG, Venkatesan S, Myles PR, Leonardi-Bee J, Al Khuwaitir TS, Al Mamun A, Anovadiya AP, Azziz-Baumgartner E, Baez C, Bassetti M, et al. Effectiveness of neuraminidase inhibitors in reducing mortality in patients admitted to hospital with influenza A H1N1pdm09 virus infection: a metaanalysis of individual participant data. Lancet Respir Med. 2014;2:395-404.

7. McKimm-Breschkin JL. Influenza neuraminidase inhibitors: antiviral action and mechanisms of resistance. Influenza Other Respir Viruses. 2013;7(Suppl 1):25-36.

8. Beau AB, Hurault-Delarue C, Vial T, Montastruc JL, Damase-Michel C, Lacroix I. Safety of oseltamivir during pregnancy: a comparative study using the EFEMERIS database. BJOG. 2014;121:895-900.

9. Berveiller P, Mir O, Vinot C, Bonati C, Duchene P, Giraud C, Gil S, Treluyer JM. Transplacental transfer of oseltamivir and its metabolite using the human perfused placental cotyledon model. Am J Obstet Gynecol. 2012;206:92 e1-6.

10. Dunstan HJ, Mill AC, Stephens S, Yates LM, Thomas SH. Pregnancy outcome following maternal use of zanamivir or oseltamivir during the 2009 influenza a/H1N1 pandemic: a national prospective surveillance study. BJOG. 2014;121:901-6.

11. Wollenhaupt M, Chandrasekaran A, Tomianovic D. The safety of oseltamivir in pregnancy: an updated review of post-marketing data. Pharmacoepidemiol Drug Saf. 2014;23:1035-42.

12. Xie HY, Yasseen AS 3rd, Xie RH, Fell DB, Sprague AE, Liu N, Smith GN, Walker MC, Wen SW. Infant outcomes among pregnant women who used oseltamivir for treatment of influenza during the H1N1 epidemic. Am J Obstet Gynecol. 2013;208:293 e1-7.

13. Greer LG, Sheffield JS, Rogers VL, Roberts SW, McIntire DD, Wendel GD Jr. Maternal and neonatal outcomes after antepartum treatment of influenza with antiviral medications. Obstet Gynecol. 2010;115:711-6.

14. Donner B, Niranjan V, Hoffmann G. Safety of oseltamivir in pregnancy: a review of preclinical and clinical data. Drug Saf. 2010;33:631-42. 
15. Saito S, Minakami H, Nakai A, Unno N, Kubo T, Yoshimura Y. Outcomes of infants exposed to oseltamivir or zanamivir in utero during pandemic (H1N1) 2009. Am J Obstet Gynecol. 2013;209:130.e1-9.

16. Graner S, Svensson T, Beau AB, Damase-Michel C, Engeland A, Furu K, Hviid A, Haberg SE, Molgaard-Nielsen D, Pasternak B, et al. Neuraminidase inhibitors during pregnancy and risk of adverse neonatal outcomes and congenital malformations: population based European register study. BMJ. 2017:356:;629.

17. Schmidt M, Pedersen L, Sorensen HT. The Danish civil registration system as a tool in epidemiology. Eur J Epidemiol. 2014;29:541-9.

18. Knudsen LB, Olsen J. The Danish medical birth registry. Dan Med Bull. 1998; 45:320-3.

19. Schmidt M, Schmidt SA, Sandegaard JL, Ehrenstein V, Pedersen L, Sorensen $H T$. The Danish National Patient Registry: a review of content, data quality, and research potential. Clin Epidemiol. 2015;7:449-90.

20. Kildemoes HW, Sorensen HT, Hallas J. The Danish National Prescription Registry. Scand J Public Health. 2011;39:38-41.

21. Larsen H, Nielsen GL, Bendsen J, Flint C, Olsen J, Sorensen HT. Predictive value and completeness of the registration of congenital abnormalities in three Danish population-based registries. Scand J Public Health. 2003;31:12-6.

22. Olsen M, Garne E, Svaerke C, Sondergaard L, Nissen H, Andersen HO, Hjortdal VE, Johnsen SP, Videbaek J. Cancer risk among patients with congenital heart defects: a nationwide follow-up study. Cardiol Young. 2014;24:40-6.

23. Savitz DA, Hertz-Picciotto I, Poole C, Olshan AF. Epidemiologic measures of the course and outcome of pregnancy. Epidemiol Rev. 2002;24:91-101.

24. Lawlor DA, Tilling K, Davey Smith G. Triangulation in aetiological epidemiology. Int J Epidemiol. 2016:45:1866-86.

25. Austin PC. A tutorial and case study in propensity score analysis: an application to estimating the effect of in-hospital smoking cessation counseling on mortality. Multivariate Behav Res. 2011;46:119-51.

26. Buhimschi CS, Weiner CP. Medications in pregnancy and lactation: part 1 . Teratology. Obstet Gynecol. 2009;113:166-88.

27. Dusetzina SB, Brookhart MA, Maciejewski ML. Control outcomes and exposures for improving internal validity of nonrandomized studies. Health Serv Res. 2015;50:1432-51.

28. Jepsen P, Skriver MV, Floyd A, Lipworth L, Schonheyder HC, Sorensen HT. A population-based study of maternal use of amoxicillin and pregnancy outcome in Denmark. Br J Clin Pharmacol. 2003:55:216-21.

29. Dreier JW, Andersen AM, Berg-Beckhoff G. Systematic review and metaanalyses: fever in pregnancy and health impacts in the offspring. Pediatrics. 2014;133:e674-88

30. Weiss NS. Can the "specificity" of an association be rehabilitated as a basis for supporting a causal hypothesis? Epidemiology. 2002;13:6-8.

Ready to submit your research? Choose BMC and benefit from:

- fast, convenient online submission

- thorough peer review by experienced researchers in your field

- rapid publication on acceptance

- support for research data, including large and complex data types

- gold Open Access which fosters wider collaboration and increased citations

- maximum visibility for your research: over $100 \mathrm{M}$ website views per year

At $\mathrm{BMC}$, research is always in progress.

Learn more biomedcentral.com/submissions 